\title{
Representações sociais, instituições e conflitos na gestão de águas em territórios rurais ${ }^{1}$
}

RODRIGO CONSTANTE MARTINS *

Apresentação

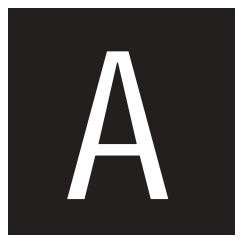

criação de mecanismos alternativos de regulação das relações entre sociedade e natureza vem revelando novos temas para o debate sobre o desenvolvimento rural. Entre tais temas, tem recebido especial destaque aqueles relativos à democracia decisória e à participação de distintos segmentos sociais na construção de metas socio-territoriais para as áreas rurais. Ressaltando a importância da categoria localidade, vários trabalhos vêm debatendo o funcionamento das instituições descentralizadas, de gestão dos recursos naturais e dos territórios rurais.

No estado de São Paulo, uma das expressões dessa descentralização institucional são os Comitês de Bacias Hidrográficas. Criados como colegiados regionais formados por diversos segmentos sociais, esta inovação institucional segue evidenciando, em que pese seu avanço na direção contrária ao centralismo decisório de outrora, certas fragilidades quanto aos seus sistemas de representação social e de construção de intervenções políticas. Em determinadas circunstâncias, tem sido possível constatar que a democracia

* Sociólogo, mestre em Ciências Sociais e doutor em Ciências da Engenharia Ambiental (área: sociologia ambiental) pela USP. Atualmente é bolsista de pós-doutorado-FAPESP no Programa de Pós-Graduação em Ciências Sociais da U FSCar, sob supervisão da Dra. Maria Aparecida de Moraes Silva. Brasil.

1Este trabalho foi realizado com suporte técnico-financeiro da Fundação de Amparo à Pesquisa no Estado de São Paulo (FAPESP). 
formal presente na composição destas modalidades de instâncias de gestão pode não resistir às relações de poder fixadas nos territórios.

Circunscrito a tal perspectiva, o presente artigo tem como objetivo geral apresentar uma análise sociológica sobre as contradições territoriais e político-institucionais na gestão das instâncias regionais de política de águas no estado de São Paulo. Propõe-se a interpretar como distintos interesses agrícolas relacionam-se com instrumentos modernos de regulação pública ambiental. Esta problemática será desenvolvida através da análise de um estudo de caso, realizado com recursos de técnicas qualitativas de pesquisa social, sobre a participação do segmento agrícola do município de Barra Bonita na estrutura regional de governança dos recursos hídricos.

Em nível analítico, tal temática será abordada através de uma reflexão crítica sobre as novas institucionalidades de gestão de águas do estado. Pretende-se, a partir das questões suscitadas no estudo de caso, realizar alguns apontamentos acerca do limites da atuação destas instâncias locais de governança ante a dinâmica territorial de dominação sociopolítica nas áreas rurais.

\section{Ruralidade e gestão socioambiental}

Muito se tem discutido, nas literaturas nacional e internacional da sociologia rural e da economia rural, sobre o fenômeno da governança dos territórios rurais. De um modo geral, tal discussão segue pautada pelas análises sobre as capacidades de os atores sociais locais criarem redes de cooperação e interesse como estratégias locais de desenvolvimento. Temas como capital social, parcerias horizontais, negociação de conflitos, interesses do entorno (ou milieu), economias locais de proximidade (clusters), entre outros, vêm sendo desenvolvidos conceitualmente tendo por refe- 
rência o que se convencionou chamar de padrões modernos de ruralidade (Marsden, 1998; Ray, 1998; Abramovay, 2000).

A problematização desses temas, contudo, segue tendo como interlocutor privilegiado o debate sobre a integridade ambiental dos territórios rurais. Neste sentido, desenvolvimento rural e gestão ambiental são concebidos como momentos de um mesmo processo, compondo uma unidade indissolúvel diante das necessidades modernas de geração de renda e uso sustentável dos recursos naturais.

Esta preocupação tem ocupado importante espaço no recente debate europeu acerca da redefinição de parte dos instrumentos da Política Agrícola Comum (PAC). Além das questões relativas aos gastos orçamentários da U nião Européia (UE) com a agricultura dos países membros - envolvendo pressões internas, favoráveis à contenção dos gastos comunitários, e externas, defensoras de uma nova conjuntura de comércio agrícola internacional - , os problemas da gestão do agroambiente têm demandado políticas e programas específicosfomentados por autoridades comunitárias, gerenciados pelas próprias localidades. Estes são os casos, por exemplo, das Cláusulas Agroambientais da PAC e dos Programas LEADER (Ligações entre Ações de Desenvolvimento da Economia Rural).

Instituídas inicialmente pela Regulação Agroambiental 2078/92 e depois ampliadas pela resolução $1257 / 99$ do Conselho da UE, as Cláusulas Agroambientais têm como principal função a incorporação de compromissos ambientais na concessão das aju das diretas aos agricultores dos estadosmembros. Sob a gerência de tais cláusulas, os agricultores incrementariam as ajudas financeiras recebidas da U E através da adesão a compromissos de emprego de métodos de produção agrícola compatíveis com a proteção ambiental e a preservação da paisagem do agroambiente. ${ }^{2}$ Por meio de tal

2 As cláusulas agroambientais não são obrigatórias nos contratos de ajudas diretas aos agricultores. Estes compromissos, firmados sob regime contratual de livre adesão entre os agricultores e o Estado, possuem um período mínimo de 5 anos de duração, sendo que seus custos de implementação são partilhados entre o Estado-membro proponente e a UE, que limita sua participação em, no máximo, $75 \%$ do orçamento total do programa. 
política, a UE estaria influindo não somente sobre o perfil das práticas agrícolas dos países comunitários, mas também sobre os próprios níveis de renda das comunidades rurais (EURO PEAN CO M M ISSIO N, 1999; BULLER, 2000).

Contudo alguns estudos têm demonstrado as assimetrias dos resultados atingid os pelos programas agroambientais de alguns países da UE. W ilson et. al. (1999), por exemplo, comparando as políticas agroambientais da Alemanha e da Espanha, ressaltam que o relativo sucesso dos programas alemães deve-se fundamentalmente a dois fatores não excludentes, quais sejam, o aporte de recursos financeiros que o governo alemão se dispôs a investir nos programas agroambientais e a estrutura de gestão administrativa de tais programas, estruturados de forma descentralizada e participativa. Já na Espanha, além do baixo aporte de recursos para a execução dos programas agroambientais, os embates políticos estabelecidos entre as várias instâncias de implementação dos programas fizeram com que a agricultura espanhola pouco avançasse em termos de mudança de suas práticas produtivas. A este respeito, M azorra (2001) destaca a disputa corporativa entre as instâncias de implementação dos programas espanhóis. No mais das vezes, tais disputas expõem o choque de interesses entre autoridades agrícolas - que buscam resguardar seus espaços de contato direto com os agricultores, através das consultas técnicas e do fornecimento dos tradicionais subsídios públicos - e as autoridades ambientais, mais atreladas à estrutura bucrático-estatal e prontas a disputar espaços de intervenção entre os agricultores para a disseminação de técnicas agrícolas distintas daquelas do receituário agronômico tradicional.

Já nos programas LEAD ER, criados pela O CDE em 1991 como iniciativa de dinamização das áreas rurais tidas como economicamente "menos favorecidas", um dos eixos de ação diz respeito justamente à conservação do ambiente natural e das heranças culturais das áreas rurais. A proposição 
de novas estratégias de desenvolvimento rural pelo programa vem buscando sobretudo estabelecer a cooperação entre os atores locais que desejam valorizar as potencialidades de seu território. A cooperação interterritorial, como estratégia de desenvolvimento local, também vem sendo estimulada pelos programas LEADER, que objetivam, inclusive, formar "redes" de territórios rurais no interior da União Européia, investindo num desenvolvimento conjunto, coordenado e atento para as especificidades regionais (LEADER EU RO PEAN O BSERTATO RY, 1999).

Todavia, segundo Storey (1999), algumas dificuldades locais têm sido geradas pelos próprios modelos formais de parceria estabelecidos pelo LEADER junto às comunidades rurais. Isto porque os modos específicos de interação dos membros das comunidades não são simplesmente transformados por metas institucionais. A identidade dos grupos sociais fixados no território também é construída através das contradições sociais. Por esta razão, o concerto pacífico de interesses pretendido por estes programas se defronta, em distintos momentos, com tais impasses, evidenciando, segundo o autor, que a solução técnica das parcerias para a construção de estratégias locais de desenvolvimento pode constituir-se, em circunstâncias específicas, como novo elemento de desigualdade social na localidade.

No Brasil, a construção de parcerias locais para a definição de estratégias de desenvolvimento e de gestão dos recursos naturais nas áreas rurais também tem sido recorrentemente abordada em nível acadêmico e institucional. A diversificação daseconomias regionais (VEIGA, 2001), a criação de novas institucionalidades de gestão territorial e ambiental (Campanhola e Silva, 2000) e a intensificação dos mecanismos de proximidade social (Abramovay, 2000) são alguns dos temas envolvidos no debate sobre a construção de novas ruralidades no país. De um modo geral, a emergência da dimensão territorial nas estratégias de desenvolvimento se 
revela nestes temas como pilar para a superação das estratégias top-down de intervenções de políticas ambientais e de desenvolvimento rural. ${ }^{3}$

Todavia, mesmo considerando a importância da incorporação da catego ria território na construção de novas institucionalidades ru rais e ambientais, permanece premente a importância das caracterizações históricas das formações so ciopolíticas das áreas rurais brasileiras para a construção de estratégias efetivamente territoriais de gestão do espaço. Por certo, a experiência européia - particularmente aquelas associadas aos Programas LEADER revelam mecanismos interessantes de incorporação de medidas de gestão ambiental nas estratégias de desenvolvimento para as áreas rurais, sejam estasáreas ainda predominantemente agrícolas, sejam elaseconomicamente dinamizadas por novos segmentos produtivose/ou por setores de serviços. Contudo, cada formação social possui um modo particular de filtragem e incorporação de processos modernizantes. Isto significa que, no caso brasileiro, as histórias distintas de nossas várias sociedades rurais deverão compor quadros heterogêneos de iniciativas locais de desenvolvimento e de incorporação da temática ambiental na gestão dos próprios territórios. ${ }^{4}$

Estas heterogeneidades podem ad quirir cores mais nítidas se considerarmos que, conforme nos sugere Candido (1998) em seu estudo clássico sobre as transformações dos meios de vida do caipira paulista, para cada sociedade, em um determinado momento histórico, há uma equação necessária de ajustamento da organização social sobre circunstâncias específicas

\footnotetext{
3 A propósito do debate mais específico sobre a relevância da categoria território na formulação de políticas públicas, ver Schneider (2004). Para o tratamento das várias abordagens desta dimensão territorial no debate nacional sobre novas ruralidades e estratégias de gestão ambiental, ver M artins (2004a), em especial capítulo 4, intitulado "Regulação Ambiental e Desenvolvimento Rural".

4 Yliskylã-Peuralahti (2003) ressalta que, do ponto de vista da gestão ambiental, é de fato relevante a construção de esferas públicas que visem a composição dos interesses agrícolas com os dos demais setores sociais interessados na dinamização das estruturas de produção de valor nas áreas rurais. Todavia, para a autora, a discussão em torno da própria gestão ambiental deve relativizar, em nível local, a ênfase sobre questões técnicas que, além de criarem ilusões de que estariam acima dos interesses de grupos sociais, também não contribuem para que a diversidade sociocultural dos territórios possa favorecer a governança local.
} 
da realidade biofísica. Isto significa que a tecnologia e as práticas produtivas de cada formação social também estão articuladas às suas formas de produção simbólica sobre o ambiente. Este processo gera uma identidade de percepção e apropriação dos recursos, com acessos e práticas de manejo dos ecossistemas, socialmente sancionados. A cultura constitui, neste sentido, um conjunto de processos mediadores entre as determinações históricas, políticas e econômicas sobre o uso dos recursos ambientais.

Partindo de tal perspectiva, parece-nos pertinente considerar a hipótese de que a construção local de estratégias de gestão dos recursos do território tende a refletir a conjuntura sociopolítica da própria localidade. O u seja, os sistemas de idéias, saberes, percepções e de capacidades de inovação construídos pela sociedade local e pretendidos como alicerce para a construção de estratégias de governança dos recursos do território, não estão dissociados das estruturas locais de dominação política e econômica.

Por certo, a problematização de tal hipótese exige o confronto dos pressupostos de gestão descentralizada e participativa dos territórios rurais e de seus recursos naturais, com as realidades locais, reprodutoras de relações específicas de dominação no âmbito territorial. Lançando mão da terminologia de Foucault (2003) para a microfísica das relações de dominação social, tratar-se-ia da análise sobre os modos como as redes locais de poder cheguem até as instituições. Sob esta perspectiva, o poder é apreendido em rede, em formação, e é precisamente por desenvolver-se como movimento que as relações de domínio produzidas fora de ambientes institucionais relacionam-se com esses ambientes, tornando-os úteis à própria dinâmica sociopolítica local. ${ }^{5}$

A seguir, apresentaremos um estudo de caso que desenvolve tal problemática a partir do tema das disputas sociais pelo acesso à água. Sob a exercer esse poder e de sofrer sua ação; nunca são o alvo inerte ou consentido do poder, são sempre centros de transmissão. Em outros termos, o poder não se aplica aos indivíduos, passa por eles. (FO U CAU LT: 1989: 183) 
perspectiva do território, buscaremos compreender como os interesses de um segmento usuário dos recursos hídricos - quais sejam, os dos agricultores - vêm sendo assimilados pelas novas institucionalidades de gestão do recurso (notadamente os Comitês de Bacias Hidrográficas). Procuraremos interpretar dois momentos do que chamaremos de dialética do território: primeiramente, trataremos do modo como a participação dos agricultores nestas estruturas descentralizadas de gestão é concebida pelos distintos segmentos da agricultura local, e, posteriormente, abordaremos as contradições do perfil concreto dessa participação.

Território, cultura local e interesses agroindustriais: um estudo de caso, espaço, método, agentes e instituições

O espaço foco, do estudo de caso analisado neste artigo, é o município de Barra Bonita, localizado na região central do estado de São Paulo. Fundado em 1912, o município, até 1930, tinha a cafeicultura como principal atividade produtiva. Em meados do último século, a cultura canavieira passou a ganhar espaço crescente na economia regional, tendo sido impulsionada principalmente pela fixação, em 1948, de uma grande usina de açúcar e álcool no município.

Com população estimada em 37.276 habitantes, Barra Bonita faz parte da área de influência direta do reservatório da Usina Hidrelétrica de Barra Bonita, hoje sob concessão da empresa norte-americana AES (Applied Energy Services), e pertence, na estrutura estadual de gestão de águas, à Unidade de Gerenciamento de Recursos Hídricos (U GRH) Tietê-Jacaré. ${ }^{6}$ Com população total estimada em 1.233.017 habitantes, a UGRH Tietê-

$6 \mathrm{~A}$ rigor, pelas delimitações territoriais das unidades de gerenciamento de recursos hídricos do Estado de São Paulo, o município de Barra Bonita possui $69,6 \%$ de sua área total na abrangência da U GRHI do Tietê-Jacaré. O s 30,4\% restantes de sua área estão na abrangência da UGRHI do Sorocaba e Médio Tietê. Contudo, o município possui atuação apenas no Comitê de Bacia Hidrográfica do Tietê-Jacaré. 
Jacaré tem como municípios de maior expressão Bauru, Araraquara e São Carlos. As cadeias agroindustriais sucocítricas e sucroalcooleiras são responsáveis por grande parte da dinâmica econômica da região. Do ponto de vista ambiental, a área rural da unidade de gerenciamento possui alta suscetibilidade a processos erosivos, e elevada demanda de água para fins de irrigação (cerca de $58 \%$ da demanda total da unidade), o que já a coloca em situação crítica de disponibilidade hídrica (São Paulo, 2000).

Para compreender os processos sociais envolvidos na reprodução cotidiana da localidade, optamos pela adoção de procedimentos de caráter qualitativo para a pesquisa de campo. Neste caso, abrindo mão do poder de generalidade das técnicas quantitativas de pesquisa social, procuramos destrinchar algumas das relações-chave presentes nos modos de reprodução social do espaço em foco, utilizando informações obtidas por meio de coleta de relatos orais, entrevistas semi-estruturadas e observações de campo. Desta feita, a precisão da quantidade de informantes foi aqui substituída pela seletividade dos atores envolvidos na teia de relações que dinamizam a conformação territorial. 0 s informantes foram selecionados a partir dos critérios de amostragem de propósito (purposeful sampling) de Patton (2002). Esta técnica nos permitiu compor um universo amostral baseado na densidade informacional dos atores locais, ou seja, no tipo de informação que estes poderiam fornecer diante dos propósitos da pesquisa. A definição dos limites para incorporação de novos informantes seguiu os critérios de ponto de saturação para estudos qualitativos sugeridos por Taylor e Bogdan (1984) e Ragin (1994). A utilização de tais critérios fez sentido em face da necessidade de compilação do amplo conjunto de informações que investigações desta natureza permitem agregar.

A fase de campo desse estudo foi realizada no período de março de 2000 a fevereiro de 2004. 0 contato com os informantes selecionados foi realizado através dos procedimentos de sistemas de rede, tais como pro- 
postos inicialmente por Furtado, (1993) e adaptados por Martins (2004a) para estudos em comunidades predominantemente agrícolas. Esse sistema exigiu a identificação, através de idas prévias a campo, de um agente social com relações de grande amplitude horizontal, capaz de enquadrar-se como elemento-pólo da rede de informantes. 0 elemento-pólo pode mesmo não ser portador de grande densidade informacional, mas deve ser apto a inserir o pesquisador no âmbito das relações cotidianas daqueles que se constituirão em informantes de fato. No caso de Barra Bonita, a posição de elemento-pólo foi ocupada pela Associação de Fornecedores de Cana-deaçúcar, que, juntamente com outros 15 produtores de cana-de-açúcar e com a Unidade Agroindustrial do município, formaram o quadro final da rede de informantes.

A tipologia dos informantes seguiu o seguinte perfil: a) a Unidade Agroindustrial (usina); b) os médios fornecedores de cana-de-açúcar do município, com áreas superiores a 80 hectares; c) os pequenos fornecedores de cana-de-açúcar, com áreas inferiores a 79 hectares, e d) os arrendadores de terras que também compõem o mercado local de força de trabaIho temporária. Em alguns casos, o entrevistado fez parte de duas ou mais categorias, o que demonstra, per si, a complexidade da teia de relações fixada no território em questão.

A análise dos discursos extraídos por meio de entrevistas e de relatos oraisfoi desenvolvida a partir de duas perspectivas não-excludentes. A primeira delas refere-se à compreensão do senso comum local. Aqui, tomamos por referência a abordagem analítica proposta por Martins, J (2000: 59), para quem:

O senso comum é comum não porque seja banal ou mero e exterior conhecimento. Mas porque é conhecimento compartilhado entre os sujeitos da relação social. Nela o significado a precede, pois é condição de seu estabelecimento e ocorrência. Sem significado 
compartilhado não há interação. Além disso, não há possibilidade de que os participantes da interação se imponham significados, já que o significado é reciprocamente experimentado pelos sujeitos. A significação da ação é, de certo modo, negociada por eles.

A segunda perspectiva objetivou anteparar a integridade significativa dos discursos. Com tal propósito, foram mantidas nas transcrições os elementos distintivos das falas, preservando-as nos aspectos de cultura lingüística, de estilo discursivo e de imposições ideológicas. Isso porque supôs-se, partindo de Habermas (1990), que em um espaço estruturado concreta e simbolicamente, o agir comunicativo revela interações estratégicas sobre os modos de reprodução e de domínio da sociedade local. Neste sentido, mesmo as informações obtidas através da estrutura tematizada das entrevistas foram compreendidas como ações de fala, ou seja, como construções simbólicas de situações concretas. Deste modo, mesmo a despeito de terem sido registradas em um ambiente de entrevista e não, de debate de idéias, tais falas permitiram a explicitação das convergências e conflitos discursivos acerca da reprodução social do território, além de também fornecerem indícios sobre as estratégias que deverão ser tecidas pelos diversos atores em seu devir no território.

Ainda no tocante às transcrições dos relatos orais, procuramos tornar visível ao leitor o que Q ueiroz (1983) chama de espontaneidade do relato, ou seja, as manifestações não-lingüísticas do relator, que decorrem de sua própria reflexão, sem influências alheias - como, por exemplo, as do entrevistador. ${ }^{7}$ Deste modo, as citações orais presentes no texto também indicarão eventuais comportamentos espontâneos manifestados pelo informante quando da coleta de seu relato.

7 A rigor, a simples presença do pesquisador com suas indagações e um instrumento de gravação do que será dito, exerce influência nos modos de manifestação do informante-relator. Contudo, como também nos esclarece Q ueiroz (1988), em pesquisa social, a finalidade do investigador não deve ser o estabelecimento da "verdade dos fatos" por via do relato do informante. Neste caso, o que importa ao pesquisador são as formas de interpretação da realidade social presentes no relato. São justamente essas formas que expressam as dimensões dos interesses, os quadros de referência, as hierarquias e os valores presentes "na encruzilhada da vida individual com o social" (Q U EIRO Z, 1988: 36). 
A instituição analisada como palco da reprodução dosinteresses sociais dos agricultores do espaço em foco foi o Comitê de Bacia Hidrográfica (CBH), em particular o Comitê de Bacia Hidrográfica do Tietê Jacaré (CBH TJ). Amparado pelo debate institucional sobre o princípio da subsidiariedade, ${ }^{8}$ o CBH é, no estado de São Paulo, componente do Sistema Integrado de Gerenciamento de Recursos Hídricos (SIGRH), criado pela Lei Estadual 7.663, de 1989. ${ }^{9}$ Também chamado de parlamento das águas, o CBH é um colegiado regional composto por diversos segmentos sociais envolvidos na gestão dos recursos hídricos. Atua na definição das prioridades, programase projetos componentes do Plano Estadual de Recursos Hídricos (PERH). Atualmente, na estrutura do SIGRH, o estado é divido em 20 Comitês de Bacias Hidrográficas.

Para o aprofundamento da análise das relações do setor agrícola de Barra Bonita com o CBH regional, empreenderemos ainda um esforço de interpretação acerca dos modos como os distintos segmentos da agricultura municipal compreendem a funcionalidade da política que deverá constituirse (segund o o próprio PERH) no principal instrumento de gestão dos $\mathrm{CBH}^{\text {'s }}$ no estado, a saber, a política de cobrança pelo uso da água. De acordo com o projeto de lei que dispõe sobre a implementação da política (projeto este que se encontra em fase final de tramitação na Assembléia Legislativa do Estado), tal cobrança garantirá aos $\mathrm{CBH}$ 's recursos financeiros para o financiamento dos programas e intervenções contemplados nos planos regionais de recursos hídricos.

Ainda que representem, em certo sentido, a emergência de padrões modernos de gestão local, alguns contextos locais evidenciam a fragilidade

8 De acordo com tal princípio, toda ação que pode ser decidida e implementada no âmbito da localidade, não deve ser submetida à decisão de nível hierárquico superior, decorrendo daí uma divisão funcional em termos de arranjos institucionais e de envolvimento dos interesses sociais locais na construção de políticas no - e não para o - território. Para pormenores sobre 0 princípio da subsidiariedade, ver Scheneider e Volkert (1999).

90 SIGRH articula, em seu funcionamento, três estruturas de gestão, quais sejam: A estrutura deliberativa, composta pelo Conselho Estadual de Recursos Hídricos e pelos Comitês de Bacias H idrográficas; a estrutura técnica, formada pelo Comitê Coordenador da Política Estadual de Recursos Hídricos, e a estrutura financeira, composta pelo Fundo Estadual de Recursos Hídricos. 
desta nova instância ante a ordem patrimonialista, ainda marcante nas formações rurais do país (M ARTINS, 2004b). No caso do estado de São Paulo e particularmente do município, foco de nosso estudo de caso, há, como veremos adiante, o predomínio dos interesses das lideranças locais atreladas ao capital agroindustrial nas instâncias regionais de gestão de águas, fato que interfere não só nas práticas administrativas do comitê, mas também na produção simbólica da sociedade local, em torno dos fenômenos associados à água - tais como a escassez, a poluição e o livre acesso ao recurso.

Em nível metodológico, convém ainda esclarecer que, por tratar-se de um estudo de caso, a história local será aqui problematizada sob o enfoque da relação entre o particulare a totalidade. O u seja, a localidade será concebida não como dedução de processos históricos universais, mas como momento da totalidade, como particularização que processa em sua relação dialética com totalidades mais amplas. ${ }^{10}$

\section{A produção de valor no território}

A dinâmica socioeconômica do município de Barra Bonita atrelou-se, ao longo dos últimos 40 anos, ao ritmo de crescimento da agroindústria sucroalcooleira do estado de São Paulo. A presença de uma grande unidade agroindustrial do setor no município foi fator decisivo nos rumos tomados pela expansão da agricultura regional na segunda metade do século XX. Em 2003, a cultura canavieira era responsável por 93\% das áreas de exploração agrícola do município - o que correspondia a cerca de 10 mil hectares de terras (Casa da Agricultura Antonio O rtigossa, 2001).

10 A respeito da análise do particular-universal em circunstâncias de localidade, a abordagem aqui empregada segue as mesmas preocupações de M artins, J. (2000: 132), para quem a história local é a história da particularidade, embora ela se determine pelos componentes universais da H istória, pelos processos mais amplos e significativos. Isto é, embora na história local raramente sejam visíveis as formas e conteúdos dos grandes processos históricos, ela ganha sentido por meio deles, quase sempre ocultose invisíveis. Cabe ao pesquisador descobrir estes nexos. A história local é certamente um momento da História, mas momento no sentido de expressão particular e localizada das contradições históricas. 
Atualmente a referida unidade agroindustrial é o principal catalisador regional de força de trabalho, possuindo um quadro de aproximadamente 6.000 funcionários, dos quais $60 \%$ formam o que os gerentes da usina chamam de "mão de obra rural", ou seja, são trabalhadores envolvidos diretamente com o plantio e a colheita da cana-de-açúcar. Somam-se a estes ainda cerca de 2.000 trabalhad ores contratad os temporariamente no período de safra e antigos trabalhadores que, após serem demitidos pela usina ao longo da primeira metade da década de 90 , formaram cooperativas de prestação de serviços para a própria empresa, desempenhando, no mais das vezes, a mesma atividade exercida nos tempos de funcionários efetivos. $^{11}$

Entre os anos de 2000 e 2003, a usina utilizou anualmente uma área de cerca de 77 mil hectares de produção agrícola, dos quais 18 mil eram de propriedade da empresa e 59 mil provinham de terras arrendadas. Nessa área, que abrangia territórios de seis municípios - Barra Bonita e outros cinco circunvizinhos-, a usina produziu anualmente cerca de 6 milhões de toneladas de cana-de-açúcar. A esses, somavam-se, ainda, cerca de 1 miIhão de toneladas adquiridas junto a fornecedores, localizados em um raio de $75 \mathrm{~km}$ da usina. ${ }^{12}$

Todos os fornecedores de Barra Bonita pertencem a uma Associação Regional de Fornecedores, com sede no próprio município. Em entrevistas com a direção da associação e com alguns de seus fornecedores, pôde-se

$11 \mathrm{Na}$ realidade, essas cooperativas de trabalhadores surgiram como efeito do programa de terceirização de serviços da empresa. Um dos exemplos mais elucidativos deste processo foi a terceirização dos serviços de transportes da usina. Conforme nos explicou o gerente de recursos humanos da empresa, a usina manteve sua frota de veículos, mas os funcionários do setor foram desvinculados exatamente para se tornarem prestadores de serviço. Assim, a usina passou a estabelecer com os mesmos um contrato de locação de veículos e esses, por sua vez, estabeleceram com a usina contratos de prestação de serviços de transportes. Embora o gerente alegue que esses trabalhadores se tornaram "microempresários", a realidade é que, se a relação jurídica destes com a empresa mudou, sua dependência para com as estratégias de acumulação permanece, visto que seu instrumento de trabalho - qual seja, o caminhão - permanece sob posse da usina.

12 Segundo a gerência da empresa, este volume de cana ocupa pouco mais de $80 \%$ da capacidade industrial de moagem instalada na usina. 0 patamar máximo de processamento industrial, que gira em torno de 8 milhões de toneladas, foi atingido em meados dos anos 80, e atualmente confere à usina o título de maior unidade produtora de açúcar eálcool do mundo (CASA DA AGRICU LTURA ANTO NIO ORTIGOSSA, 2001). 
observar que a entidade se destaca menos por sua atuação política de defesa dos interesses dos associados junto à usina do que por seu quadro de prestação de serviços, dos quais se destacam a assistência médica e hospitalar e os descontos em vários ramos do comércio local.

Dosatuais 1.012 fornecedores associados, 145 são do município de Barra Bonita. Não obstante a proximidade geográfica com a sede da usina condição que poderia também corresponder a laços mais estreitos de parceria - , a relação desses fornecedores com a empresa tem sido permeada por níveis distintos de tensão. Em grande medida, tal tensão associa-se ao pequeno volume de cana que a maior parte desses fornecedores dispõe anualmente para comercializar com a empresa, fato que, de antemão, dá um indicativo da importância da variável estrutura fundiária na compreensão do movimento de produção de valor neste espaço.

Do total de fornecedores do município de Barra Bonita, 8 possuem mais de 80 hectares de lavoura de cana-de-açúcar, sendo que, destes, apenas 1 possui área superior a 200 hectares. Neste seleto grupo de fornecedores, todos produzem cana na região há pelo menos 20 anos, sendo que os produtores mais novos, conforme definição dos próprios, são "herdeiros da atividade do pai". 0 utros 6 produtores que possuem área agrícola entre 50 e 80 hectares estão atualmente arrendando suas propriedades para a usina. Já o número de fornecedores cadastrados com área agrícola inferior a 80 hectares no município caiu, de acordo com os dados da Associação regional, de 216 para 131 fornecedores desde 1995 - uma retração de 37\% em praticamente uma década. Deste montante, a grande maioria arrendou terras para a usina. ${ }^{13}$

130 contrato de arrendamento estabelecido entre a usina e os proprietários de áreas agricultáveis segue a forma de arrendamento em dinheiro, no qual a empresa paga um preço fixo por hectare utilizado, independentemente das condições de fertilidade do solo ou da proximidade da área agrícola em relação aos cursos d'água da região. 
Eentre as razões alegadas pelos pequenos agricultores para optarem pelo arrendamento de área agrícola, destacam-se as dificuldades de investimento na produção e particularmente aquelas relativas aos investimentos para a adoção de técnicas de irrigação. Isto porque, diante da recorrência de longos períodos de estiagem na região, a irrigação se tem tornado fator essencial para a garantia da colheita agrícola. No caso da usina, titular das lavouras próximas aos principais cursos d'água do município (incluindo as margens do reservatório da UHE de Barra Bonita), o emprego das técnicas de irrigação é um incremento de capital; no caso destas pequenas unidades de produção agrícola, organizadas em sua maioria a partir da base familiar, a ausência de tecnologia é uma restrição adicional à sua reprodução social.

$\mathrm{Na}$ avaliação dos gerentes da unidade agroindustrial do município, neste movimento de centralização de capital, os pequenos fornecedores que assumiram a função de arrendadores de terras para a empresa tornaram-se isentos de gastos e demais responsabilidades sobre o perfil técnico da produção, além de ainda terem garantido renda pelo interesse da empresa em cultivar suas terras. Não obstante tal avaliação, esta política de arrendamento da empresa surge para os menores fornecedores não como opção, ou seja, como alternativa diante de um leque de possibilidades, mas sim como condição única de se manterem atrelados ao movimento de produção de valor naquele território. Caso contrário, provavelmente, tornar-se-iam novos membros do processo de mobilidade espacial característico da modernização da produção canavieira do estado de São Paulo. ${ }^{14}$ 
Em alguns casos, estes pequenos arrendadores assumem nova condição subalterna de participação na produção local de valor excedente, qual seja, a de força de trabalho temporária da própria empresa arrendatária.

Entre produzir e dever pra banco, ou arrendar terra para a usina, eu prefiro arrendar. Não porque eu ganho dinheiro assim, porque o que eles pagam também não dá pra viver. Mas pelo menos eu tenho tempo livre pra fazer bicos na cidade e colher cana por aí. Esse último ano aí eu colhe cana quase que só pra usina mesmo! (Arrendador/trabalhador temporário, 30 anos)

O grau de dependência dos pequenos fornecedores para com a usina é reforçado pela dificuldade de comercialização da colheita com compradores de fora da região. O s custos de transporte com os quais estes agricultores teriam que arcar são apontados como um dos empecilhos à busca de novos mercados. Além disso, o funcionamento do mercado local de comercialização das safras corresponde a um monopsônio (ainda que as condições formais de livre comércio permaneçam presentes na região), situação que os fornecedores preferem preservar, mesmo que isso signifique a reiteração de relações de domínio social.

Infelizmente, nós não temos mais onde recorrer. $N$ ão tem mais o instituto. ${ }^{15} \mathrm{~N}$ ão tem mais órgão do governo que olhe pra isso aqui. Todo dia vem comprador de cana aqui. Eles pagam bem a tonelada [enfático]. Chegam no canavial e calculam, dá o dinheiro e corta a cana. Hoje mesmo veio um rapaz querendo comprar

\footnotetext{
150 instituto a que se refere o agricultor é o IAA (Instituto do Açúcar e do Álcool), extinto no início da década de 90 pelo governo Collor. Até então, o IAA se havia caracterizado como um importante intermediador nas disputas entre plantadores de cana e usinas. Atuava na negociação de problemas relacionados ao preço da cana, no levantamento dos estoques das usinas para reajuste do preço da cana e no levantamento de dados técnicos e produção genética, entre outros. Para uma análise pormenorizada do histórico do IAA e dos impactos de sua extinção na correlação de forças na agroindústria sucroalcooleira, ver Alves e Assumpção (2002).
} 
aqui 2 mil toneladas nossa. Masnósnão vamos vender. Como nós vamos vender? A gente vive da cana, sempre vendeu pra usina. Mesmo com as dificuldades, as dívidas - e a gente tá devendo bastante - a gente tem contrato com a usina. Nosso contrato é de seis anos. $E$ se no ano que vem acontece a crise desses anos atrás, e se a usina fala "eu não quero a sua cana, você já vendeu pra outro, agora vai vender lá". Eles podem falar assim, não pode? E como nós vamos fazer? (Agricultorfornecedor, 73 anos)

Diferentemente do que ocorre com os maiores fornecedores da usina - que compram insumos diretamente da rede de fabricantes-, é no ato da comercialização da safra que os pequenos fornecedores adquirem os insumos necessários para a próxima colheita. Essa aquisição também é feita diretamente com a usina, que fornece, na maior parte das vezes, agroquímicos (sobretudo herbicidas) como parte do pagamento da safra do agricultor. Tal troca assume particular importância na medida em que orienta decisivamente a conduta do fornecedor no momento da realização de sua mercadoria: nesta relação são reafirmadas não só sua condição de subsunção ante a cadeia agroindustrial, mas também o perfil técnico a ser seguido por este agricultor.

\section{Novas institucionalidades ambientais e dominação territorial}

A despeito de a região de Barra Bonita enfrentar atualmente uma situação crítica de disponibilidade hídrica, os responsáveis pela produção agrícola da usina têm enfatizado a crescente necessidade de se expandirem o conhecimento e as técnicas de plantio da cana irrigada na região. Isto porque, nos últimos três anos, a diminuição das chuvas tem afetado o de- 
sempenho das lavouras, elevando o tempo de maturação da cana em alguns casos e, em outros, causando mesmo queda de produtividade. Nesse período, a usina e seu maior fornecedor (com cerca de 480 hectares de lavouras de cana) realizaram a chamada "irrigação de choque", qual seja, aquela desenvolvida em locais pontuais da lavoura, onde a necessidade imediata de água é premente. Evidentemente, esta modalidade de irrigação não pôde ser praticada pelos pequenos fornecedores do município, visto que sua realização implicaria o uso de tecnologias restritas àqueles produtores com elevado nível de capitalização. No caso da usina, as normas legais de requisição de outorga para a captação de água foram ignoradas. No caso do fornecedor, além de desconhecer tais normas, a reação em saber, através do entrevistador, da existência de tal aparato legal, foi motivo de indignação.

Nós conhecemos os procedimentos e somos favoráveis. Cumprimos os procedimentos aqui na usina, em nossa divisão industrial. Agora na lavoura, no meio do canavial, se o regulamento quiser ser cumprido ele terá que entrar lá. Tem que cruzar o canavial na hora que for![enfático]. Q uem trabalha com agricultura sabe que é assim que a coisa funciona. Eu não posso pedir pra planta esperar o fiscal chegar. É preciso haver bom senso aí. (U nidade Agroindustrial)

Por que eu tenho que pedir licença pra alguém pra tirar água do rio? 0 rio não tem dono! E se tiver dono, o dono que apareça e venha falar comigo [fala austera]. É como aqui na minha casa: se alguém entra para levar algo que é meu, eu vou atrás e garanto o meu direito de dono. Agora, onde está o dono da água? Só faltava alguém querer ser o dono da água! Nem eu, nem você, nem governo; ninguém pode ser dono disso! A água está aí para gente sobreviver, produzir alimento. [...] Eu não estou sujando a água, nem nada. $E$ 
mesmo que estivesse, o governo que mande a Cetesb vir aqui me multar. Não é ela que faz isso? Então, eles que venham atrás, não sou eu quem tem que ir atrás deles. (Fornecedor, 71 anos)

No depoimento da gerência da usina, é sintomático o modo como a empresa espera que a regulamentação do acesso à água se adapte ao ritmo temporal de sua estrutura de produção de valor. 0 canavial é representado como um universo obscuro que deve ser enfrentado em toda sua robusteza pela fiscalização ambiental. A previsibilidade característica da modernização das práticas agrícolas capitalizadasé, neste momento, deixada de lado em prol da urgência da planta. Tal urgência, que em outras circunstâncias poderia ser racionalmente calculada por meio de técnicas agronômicas, é alçada à condição de argumento supostamente irrefutável para o não cumprimento dos dispositivos legais. Sem embargo, esta situação inimaginável na agricultura moderna, com o administrador agrícola descobrindo quase por eventualidade as necessidades imediatas de água da planta, pode expressar menos uma limitação técnica efetiva do processo modernizador da agricultura regional do que um apelo discursivo rumo à justificação do acesso não legítimo da empresa ao recurso.

0 relato do fornecedor, por sua vez, revela que, embora ciente dos mecanismos tradicionais de fiscalização da qualidade dos corpos d'água vide referência à Cetesb (Companhia de Tecnologia de Saneamento Ambiental, órgão fiscalizador da Secretaria do M eio Ambiente do governo de São Paulo) -, este desconhece as inovações institucionais operadas no sistema estadual de gestão de águas ao longo da última década. O utrossim, irrompem na fala do fornecedor pressupostos de liberdade absoluta de uso do recurso, ainda que, do ponto de vista institucional, haja restrições ao livre acesso à água desde o Código das Águas de $1934 .{ }^{16}$ No entanto

160 Código das Águas, estabelecido pelo Decreto Federal no 24.643 de 10/07/1934, assegurava o uso gratuito de qualquer corrente ou nascente de água para as necessidades básicas de sobrevivência humana, permitindo a todos o uso do recurso conforme regulamentos administrativos. Impedia, no entanto, a derivação das águas públicas para aplicação na agricultura e 
a história de acesso não arbitrado do agricultor junto ao recurso sobrepõese, no âmbito de sua experiência social, aos aparatos legais de regulação. O u seja, sua compreensão sobre seu acesso ao recurso extrapola os arranjos formais direcionados ao estabelecimento de normas de uso. Remontando à questão da propriedade, esse agricultor nada mais faz do que exigir o aparecimento de um agente que, assim como ele, defenda a parcela do território que lhe pertence. Contudo, embora tenha claro seu direito de propriedade de terras, o agricultor insinua uma defesa quase rousseauniana do livre acesso ao recurso natural que torna possível a utilização produtiva da terra, e conclui: "ninguém pode ser dono disso". ${ }^{17}$

Já entre os pequenos agricultores do município, há um nítido desconhecimento sobre o sistema estadual de gestão de águas. A quase totalidade dos agricultores entrevistados não tem esclarecimento sobre a participação dos usuários de recursos hídricos no sistema. Alguns agricultores chegam mesmo a ignorar a existência dos Comitês de Bacias H idrográficas, e, para os que já ouviram falar neste termo, é comum identificá-lo como órgão governamental frio e distante, ou seja, fazendo uso da terminologia weberiana, como instância de poder burocrático-administrativa, que atua presumidamente com indiferença ante as circunstancialidades dos interesses do cotidiano local.

Q uando esclarecidos sobre as funções do comitê e a possibilidade de participação efetiva do segmento agrícola na instância de gestão, os até então desconheced ores da estrutura já vislumbram a nova instituição a partir das relações de dominação da agricultura local:

indústria, sem a existência de concessão. De um modo geral, embora se tenha constituído no primeiro passo rumo a um modelo burocrático de gerenciamento das águas no Brasil, o Código de Águas limitava-se às ênfases nos temas relativos ao abastecimento da região semi-árida brasileira e ao aproveitamento hidroenergético das demais regiões do País. A propósito, ver Freitas (1997)

17 A passagem que segue é elucidativa sobre os traços rousseaunianos do depoimento do agricultor. Refletindo sobre o surgimento das relações de propriedade da terra, o filósofo francês conjectura que "o verdadeiro fundador da sociedade civil foi o primeiro que, tendo cercado um terreno, lembrou-se de dizer isto é meu e encontrou pessoas suficientemente simples para acreditá-lo. Q uantos crimes, guerras, assassinatos, misérias e horrores não pouparia ao gênero humano aquele que, arrancando as estacas ou enchendo o fosso, tivesse gritado a seus semelhantes: Defendei-vos de ouvir esse impostor; estareis perdidos, que os frutos são de todos e que a terra não pertence a ninguém." (ROUSSEAU: 1991: 259) 
Nessa parte que envolve a política aí é a usina quem deve entrar. Eles irrigam cana, precisam de água pra muita coisa lá dentro. Água mesmo nós não usamos aqui. A gente não tem as máquinas pra isso. Agora a usina sim. Aqui ninguém vai discutir isso com eles. Acho que é até por isso que a gente não conhece esse comitê. Mas a usina deve conhecer e esse comitê também tem que conhecer a usina, pois é só ela que tira água do lado de cima do Tietê. (Agricultor-fornecedor, 48 anos)

O "lado de cima do Tietê" a que se refere o agricultor é justamente a região do reservatório da U HE de Barra Bonita. As áreas marginais ao reservatório são ocupadas quase exclusivamente pela usina, seja com propriedades próprias ou arrendadas. Do ponto de vista da produção de valor, a localização das lavouras da usina em relação ao reservatório segue historicamente conferindo à empresa um diferencial de acumulação. Isto por conta das condições de fertilidade dos solos das margens do reservatório e do próprio clima da região. Conforme a gerência da empresa.

O montante deste volume [de produção] está ligado a uma região que produz cana em uma época em que normalmente a cana não está pronta ainda em outras regiões [...] Este vale do Tietê, onde existe a bacia de acumulação da represa, tem um tipo de solo com uma fertilidade muito boa, e nos permite esta vantagem. (Unidade Agroindustrial)

Deste modo, enquanto a colheita da produção de cana-de-açúcar no estado de São Paulo se inicia normalmente no final do mês de maio e se encerra no final do mês de outubro, a usina inicia a sua colheita no início de abril, encerrando-a no final de dezembro. Em virtude desta singularidade, a empresa construiu, ao longo de seu processo de acumulação, uma estrutura industrial que lhe permite absorver o total da cana colhida ao longo deste 
tempo estendido, o que também repercutiu em um modo mais intenso de exploração da força de trabalho (temporária e permanente) em sua produção. ${ }^{18}$

Para aqueles agricultores que conhecem um pouco da estrutura estadual de gestão de águas, há um nítido desestimulo em tomar seu espaço como representante no segmento sociedade civil neste sistema. A título de ilustração, vale citar o caso de um dos membros da direção da Associação de Fornecedores, que nos relatou ter sido recentemente convidado para participar das reuniões do CBH-TJ, mas julgou não ser prioridade para a associação dedicar-se, até o momento, ao fortalecimento do seu espaço no sistema estadual de gestão de águas. M esmo a usina, usuária de água para fins agrícola e ind ustrial, prefere não participar diretamente da estrutura de gestão. De acordo com um de seus gerentes, neste momento, a usina julga mais vantajoso observar "de fora" os rumos que essa nova estrutura de gestão irá tomar. Ademais, conforme o depoimento a seguir, a unidade agroindustrial confia seus interesses setoriais a uma organização corporativa com forte influência no cenário da atividade agroindustrial do estado:

Nós não estamos nos envolvendo diretamente no comitê, mas temos quem nos represente. A Unica tem assento por lá e defende os interesses de todo o nossos setor. Com eles dentro do comitê, não temos por que deslocar alguém para lá. [...]. Estamos absolutamente representados. Nós e toda a região, pois existe uma convergência de interesses para se gerar renda pra essa gente. (U nidade Agroindustrial)

N estas circunstâncias, a usina pode amparar-se, no que se refere aos seus interesses de acesso aos recursos hídricos regionais, na representação corporativa desempenhada pela U nião da Agroindústria Canavieira de São Paulo (Unica) junto ao CBJ-TJ. ${ }^{19}$ Contudo é notório que esta entidade

18 A propósito do histórico da modernização da agricultura na área de influência do reservatório de Barra Bonita e de suas repercussões so bre as relações de trabalho na região, ver M artins (2000).

19 A outra entidade que possui vínculo com a agricultura e que tem representação no CBH-TJ é a Associação Brasileira de Exportadores de Cítricos. 
corporativa de representação setorial partilha interesses com a unidade agroindustrial e não, com o conjunto dos atores sociais envolvidos na produção sucroalcooleira. Os pequenos agricultores fornecedores da usina, por exemplo, não se encontram no espectro dos interesses da U nica. 0 fato de quase a totalidade dos fornecedores com áreas de lavouras inferiores a 79 hectares ter dificuldades de acesso à água para uso produtivo, por exemplo, não é um tema abordado pelos representantes do setor sucroalcooleiro no comitê. ${ }^{20}$ Sob tais circunstâncias, o comitê se torna um instrumento de construção de vantagens econômicas para grupos sociais historicamente articulados e tradicionalmente hegemônicos em territórios específicos.

Além da falta de conhecimento sobre a estrutura do comitê e sobre as possibilidades de participação do segmento agrícola na gestão das águas regionais, também é notório, entre os pequenos fornecedores da usina, 0 desconhecimento sobre os principais instrumentos de gestão de águas, utilizad os pelo comitê. Entre esses instrumentos, a cobrança pelo uso da água, que está em vias de aprovação pela Assembléia Legislativa do Estado de São Paulo e deverá imputar-Ihes ainda maiores restrições de acesso ao recurso, é absolutamente desconhecida pelos agricultores. ${ }^{21}$

A rigor, o projeto de cobrança pelo uso da água apóia-se no pressuposto da valoração ambiental - amparado conceitualmente nas teorias da microeconomia neoclássica - de que, ao ser levado a realizar cálculos de custo/benefício por meio de estratégias de precificação, o usuário estaria automaticamente sendo induzido a adotar comportamentos racionais de uso do recurso ${ }^{22}$. No caso paulista, os critérios de cobrança deverão ser

\footnotetext{
20 Fonte: Atas das reuniões ordinárias do CBH-TJ, disponíveis em www.sigrh.sp.gov.br

21 Sobre o contexto político da implementação da cobrança pelo uso da água junto ao setor agrícola do estado de São Paulo, ver M artinse Valencio (2003)

22 A adoção da cobrança pelo uso dos recursos hídricos tem como uma de suas orientações básicas o Princípio do Poluidor Pagador, adotado pela legislação ambiental dos países filiados à OCDE. De acordo com tal princípio, o agente social poluidor deve arcar com as despesas para manter o meio ambiente dentro de parâmetros aceitáveis de qualidade, sustentando, por
} 
elaborados pelos próprios Comitês de Bacias H idrográficas, com participação direta da sociedade civil.

A despeito da gestão descentralizada da cobrança, entre os pequenos agricultores de Barra Bonita, tal instrumento de gestão é diretamente associado ao governo estadual, cabendo apenas ao usuário pagar pela água que Ihe for necessária. A participação do usuário - garantida tanto no projeto de lei estadual que a dispõe quanto na própria estrutura deliberativa dos comitês de bacia hidrográfica - na definição dos critérios de cobrança e na determinação dos destinos da arrecadação dentro de sua bacia hidrográfica é compreendida por esses agricultores menos como realidade efetiva dentro do sistema de gestão de águas do que como retórica governamental para a legitimação de um novo modo de arrecadação monetária para os cofres públicos.

Sobre o princípio que fundamenta a cobrança - qual seja, o da valoração ambiental - a avaliação dos pequenos agricultores-fornecedores seguiu menos uma ótica coorporativa de defesa dos interesses da categoria do que uma interpretação particular dos limites de controle da sociedade em geral sobre os recursos hídricos.

O governo não pode produzir água, como ele vai cobrar por ela ? A água é de todo mundo, dos bichos, das plantas, do homem, de todo mundo que precisa. 0 governo não pode cobrar por ela [elevando o tom da voz]. O governo não pode produzir água pra querer vender. Se secar o país, o governo morre junto! o governo tem que cuidar é do esgoto que vem pra água, o esgoto da cidade. (Fornecedor/trabalhador temporário, 68 anos)

conseguinte, a concepção de que, ao ser penalizado pela cobrança no uso deletério da água, o poluidor seria induzido a adotar práticas menos onerosas ao meio ambiente. Há implícita, deste modo, outra crença neoclássica: a de que o produtor induziria o progresso técnico, respondendo rapidamente à demanda de sustentabilidade ambiental menos por considerar que tal temática seja legítima e mais porque o não atendimento à mesma reverbaria negativamente na sua inserção no mercado. Para uma apresentação pormenorizada do Princípio do Poluidor Pagador, ver Pearce e Turner (1991). A propósito de uma reflexão crítica sobre esse princípio, ver Leff (1995) e Martins (2004a). 
É difícil essa coisa de cobrar pela água, principalmente agora que tá faltando. Não tem água pra todo mundo. Agora é que o governo deveria dar um jeito de todo mundo ter água, e não deixar ninguém querer cobrar por ela. Isso poderia até ser considerado crime. Do jeito que tem aproveitador por aí, se não tomarem conta disso, logo vai ter gente querendo se aproveitar de quem não tem. [...] Você vê, é caro um pacote de farinha? Não é, mais tem muita gente que não tem dinheiro pra comprar. Essa é a realidade. Por mais que seja pouco o que se cobre pela água, vai ter gente que também não vai conseguir pagar. E quem não conseguir pagar, como fica? (Agricultor-fornecedor, 68 anos)

É marcante no depoimento desses agricultores o conjunto de representações culturais, próprio deste segmento social, que é preterido pelo princípio conceitual da valoração dos recursos naturais. Ao definir um valor monetário como indicativo da importância relativa de um recurso natural, conseqüentemente se está considerando que princípios de mercado são eficazes no direcionamento do comportamento dos grupos sociais usuários. No caso da valoração da água, é suposto que esses princípios de mercado estejam suficientemente incorporados pela sociedade, de modo a suplantar mesmo os laços culturais que, no caso de alguns grupos sociais, possam contrapor-se à lógica de significação dos processos políticos e econômicos próprios dos ambientes de mercado.

Tal movimento revela a tentativa de universalização do sujeito racional, do homo oeconomicus, que toma forma nas demonstrações neoclássicas, no planejamento da gestão estadual de águas. Não obstante, ao nortear a gestão de políticas públicas, esta lógica universalizante se dissolve em meio à diversidade de interesses e de signos sociais e às distintas temporalidades responsáveis pelas concepções variadas de relação sociedade-natureza. No caso dos agricultores supra, a resistência aos mecanismos de valoração da 
água não se refere ao preço a ser cobrado pelo acesso ao recurso ou por seu descarte. As questões levantadas pelos agricultores são de ordens absolutamente diversas, relacionadas com dimensões simbólicas que remetem tanto à concepção do trabalho social como fundamento do valor econômico quanto às circunstâncias de equidade social no acesso ao recurso.

Assim, a experiência cotidiana que os usuários do recurso construíram historicamente na região é o que influencia sobremaneira a compreensão social da lógica de valoração ambiental. É justamente sobre essa experiência que se fundamentam as assertivas dos agricultores de que somente pode ser vendido o que é produzido, trabalhado, transformado através do trabalho social, ou de que o acesso à água, assim como o acesso a um pacote de farinha, é um indicador simultaneamente material e simbólico das desigualdades sociais produzidas no território. N este caso, não se trata de um conhecimento teórico que se esforça em enquadrar a realidade contraditória da produção de valorem seus conceitos - como poderia bem sugerir uma reflexão marxista-estrutural -, mas sim, do modo de experimentação social do território e de seus recursos por via dos processos de trabalho e das práticas de comercialização também experimentadas pelos pequenos agricultores. $\mathrm{O}$ u, como nos diria Thompson (1981: 182), trata-se de práticas de pessoas que experimentam suas situações e relações produtivas determinadas como necessidades e interesses como antagonismos, e em seguida "tratam" essa experiência em sua consciência e sua cultura das mais complexas maneiras e em seguida agem, por sua vez, sobre sua situação determinada.

Sem embargo, a conduta econômico-racional universalizante que o princípio da valoração aspira a obter particularmente dos agricultores parece constituir-se em uma frágil abstração, posto que se refere apenas a um dos aspectos da complexa teia de relações que conduzem grupos sociais a determinados comportamentos ante o meio biofísico. Construções simbólicas 
como as apresentadas nos depoimentos supra são compostas de códigos particulares de conhecimento e concepções de destino também bastante definidas.

São justamente essas construções que compõem a complexidade do território. Reiterando o argumento de Leff (2003), compreender o território significa interpretar as formas distintas de construção dos modos de vida, de identidades culturais e de experiência social sobre as potencialidades ecológicas. Trata-se do espaço onde se manifestam diferentes temporalidades, diferentes formas de conciliação entre o tradicional e o moderno, entre modos distintos de apropriação e uso dos recursos naturais. No caso das áreas rurais, estas relações tornam-se ainda mais complexas, posto que a proximidade das sociedades rurais com as variadas funções ecossistêmicas permite a construção social de realidades diversas, com conjuntos de relações culturais, econômicas e políticas de ordenamento do território também bastante amplos.

Do ponto de vista analítico, conforme também sugere Godelier, é fundamental que a apreensão dos elos significativos para a compreensão da interação sociedade-natureza não se restrinja à conduta econômica; ou seja, [...] é necessário analisar cuidadosamente o sistema das representações que os indivíduos e os grupos, membros de uma determinada sociedade, formulam sobre o seu meio, pois é a partir destas representações que os indivíduos ou os grupos atuam sobre o meio. (GO DELIER; 1981: 53)

Tanto os sistemas de representações sociais interferem no tipo de conduta dos grupos sociais diante dos recursos ecossistêmicos, que a unidade agroindustrial do município de Barra Bonita, visando assegurar seu acesso à água em longo prazo, defende a precificação do recurso:

Nosso uso da água é muito particular. É difícil dizer como e quando precisaremos. [...] Nós pegamoságuas de açudes ou mesmo rios, que, quando você precisa, 
dá uma represada na hora, puxa a água, e irrigou ali tchau, desmonta e vai embora. [...] Por exemplo, eu vou utilizar a água de um determinado local, preciso utilizar a água naquele momento porque na agricultura é assim, eu não posso pedir para a planta esperar. Aí eu vou lá com o meu equipamento e como eu devo proceder? Q uem vai medir depois? E a agilidade disso? Acho que se eu for pagar eu tenho direito de exigir no mínimo a agilidade do serviço, não é? [...] Somosfavoráveis a essa cobrança neste sentido: entendemos a necessidade de racionalizar o uso da água e estamos dispostosa colaborar, mas também queremos garantias [...] na qualidade deste serviço e a garantida de que teremos água. (U nidade Agroindustrial)

A rigor, o modo como a U nidade Agroindustrial compreende o tema da valoração da água é, do ponto de vista cultural, a expressão do modo como a própria empresa experimenta suas relações cotidianas com seus trabalhadores, fornecedores e demais membros envolvidos na produção agroindustrial de valores excedentes. A relação monetária é tomada pela empresa como garantia, em longo prazo, de acesso ao recurso. N este caso, trata-se menos do entendimento sobre a racionalização do uso, do que de uma posição de heldgers por parte da usina. ${ }^{23}$

De outra parte, em termos de lógica discursiva, os valores não econômicos expostos nos depoimentos dos pequenos agricultores representam, diante das disposições estruturadas das práticas da empresa, ilhas de primitivismo ante a emergência do moderno na arena rural. Este modo de interação social, tributário da razão utilitarista própria das relações capitalistas

23 No mercado das commoditiesagrícolas, o heldgeré o agente econômico que realiza o helding, ou seja, assume uma posição de segurança no mercado de futuros contra flutuações de preços. 0 objetivo geral da operação é realizar negociações antecipadas através da suposição de situações futuras de mercado. Trata-se, para lançar mão dos conceitos de Giddens (2002) sobre a alta modernidade, de uma relação social estabelecida através de sistemas de desencaixe, nos quais tanto as fichas simbólicas (monetarização do futuro) quanto os sistemas especializados (simuladores de comportamento de mercado) garantem o estabelecimento do acordo comercial e a existência virtual dos lances projetados para mercadorias futuras. 
modernas, é composto por interesses materiais e dimensões simbólicas que divergem em muito das representações que escapam do universo dos fluxos de oferta e demanda dos mercados econômicos. Neste sentido, os princípios da valoração ambiental se relacionam estritamente com o universo e as representações sociais da empresa capitalista, ainda que, ao tornarse prática de política ambiental, seja universalizado para toda a sociedade. ${ }^{24}$ Ao prontificar-se a tal universalização, a política alicerçada nos princípios da valoração não só nega a diversidade do olhar social sobre a natureza, mas também serve às relações de dominação social fixadas nos territórios.

Isto significa que, mesmo as intervenções de política ambiental que deverão ser gerenciadas no território, como é o caso da cobrança pelo uso da água, reproduzem as desigualdades sociais da localidade. A possibilidade formal de participação dos diversos grupos sociais na gestão dos recursos hídricos encontra seus limites na própria conjuntura sociopolítica do local. No caso da valoração da água, além de sua concepção relacionar-se de antemão com um universo de representações mais próximo da empresa capitalista do que das categoriais tradicionalmente fixadas nos territórios rurais, a própria aplicação deste instrumento de gestão deverá refletir as contradições da dialética do território, posto que o gerenciamento regional de águas - através do CBH e da valoração ambiental, seu principal instrumento de intervenção - acaba sendo realizado em consonância apenas dos interesses dos grupos que têm acesso à água na região.

O utro indicador da presença marcante dos contextos sociopolíticos territoriais na gestão regional das águas é o conjunto de questões que seguem sendo pauta precípua no CBH-TJ. Neste caso, é sintomática a ausência

\footnotetext{
24 Sobre a pretensa universalização da razão utilitária, Sahlins afirma oportunamente que tal concepção, por vezes, dissimula uma disputa que é, no cotidiano, política e ideológica. N este caso, ao propor a razão universal, a explicação se satisfaz em recriar a auto-ilusão da sociedade para a qual se dirige e na qual o sistema lógico dos objetos e relações sociais segue em um plano inconsciente, manifestado somente através de decisões de mercado baseadas no preço, deixando a impressão de que a produção não passa de um precipitado de uma racionalidade esclarecida. A estrutura da economia aparece como a consequência objetivada do comportamento prático, em vez de uma organização social de coisas, pelos meios institucionais do mercado, mas de acordo com um projeto cultural de pessoas e bens. (SAH LINS, 2003: 166-167)
} 
dos temas relativos às minorias com dificuldades de acesso aos recursos hídricos nas deliberações do comitê. Como exemplo disso, cumpre destacar que, no relatório final de diagnósticos regionais para estabelecimento das diretrizes do Plano da Bacia Hidrográfica, apenas as questões técnicas relativas à qualidade dos recursose à preservação dos mananciais são contempladas (CBH-TJ, 2004b). Ademais, também na definição dos critérios de aplicação dos recursos do Fundo Estadual de Recursos Hídricos na ba$\mathrm{cia},{ }^{25}$ realizada pelo próprio comitê, as prioridades de investimento foram assim definidas: a) recursos naturais (coleta e tratamento de esgoto, recuperação de voçorocas, conservação do solo, monitoramento da qualidade/ quantidade de água, etc); b) educação ambiental e coleta seletiva de lixo; c) gestão integrada de resíduos sólidos; d) drenagem urbana e controle de inundações e, e) outros (CBH-TJ, 2004a).

Se tomarmos por referência a discussão de Santos (2002) acerca do poder como processo distributivo, exercido por constelações de relações que se reforçam ou se neutralizam e que funcionam abrindo novos caminhos ou fixando fronteiras, é possível afirmar que, neste estudo de caso, o modo fixação-de-fronteiras de exercício do domínio local desempenha função de destaque na manutenção do status quo da governança dos recursos hídricos regionais. Em síntese, podemos apontar ao menos dois processos essenciais envolvidos nesta fixação. 0 primeiro deles se refere à manutenção da situação social (e não natural) de ausência de água no cotidiano dos pequenos produtores rurais do município. Ainda que fixados em locais de acesso relativamente fácil à água, esses agricultores seguem socialmente distanciados do recurso. Tal distanciamento tem provocado, inclusive, como já indicado anteriormente, o arrendamento de novasáreas de lavoura para a U nidade Agroindustrial local.

250 Fundo Estadual de Recursos Hídricos (FEHIDRO) fornece o suporte financeiro para a operacionalização da Política Estadual de Recursos Hídricosno Estado de São Paulo. O Fundo é supervisionado por um Conselho de O rientação - o CO FEH ID RO -, que é composto paritariamente por representantes do Estado, Municípiose Sociedade Civil. 
O segundo processo de fixação-de-fronteiras está diretamente relacionado com a frágil situação desses agricultores dentro da estrutura regional de gestão de águas. Sem embargo, a falta de representação no comitê de bacia regional e o desconhecimento do modus operandi desta nova institucionalidade prejudicam sobremaneira a inclusão não só das demandas deste segmento na pauta política do comitê de bacia, mas também contribuí para a ausência de diversidades socioculturais nas propostas de construção de alternativas sustentáveis para o uso social da água nos limites da localidade. Com efeito, sem tal diversidade, dificilmente o processo de abertura-de-novos-caminhos adquirirá espaço para novas conjunturas distributivas de poder no contexto sociopolítico não somente da região de estudo, mas também de outros territórios rurais do estado.

\section{Considerações finais}

O objetivo deste artigo foi apresentar uma discussão sociológica sobre os limites territoriais da gestão descentralizada dos recursos naturais. Através de um estudo de caso, abordou-se o tema da gestão de águas nas áreas rurais do estado de São Paulo, pontuando alguns dos processos sociais envolvidos na construção de instâncias locais de governança territorial.

Conforme discutido ao longo do texto, a problematização da dinâmica sociopolítica dos territórios é de fundamental importância para a avaliação dos limites das novas institucionalidades de gestão socioambiental. 0 caso de Barra Bonita evidenciou que, de fato, as conjunturas locais de exclusão social tendem a serem refletidas nas instâncias descentralizadas de gestão dos recursos territoriais. As estruturas decisórias descentralizadas de gestão de águas - notadamente os Comitês de Bacias H idrográficas - , embora tecnicamente elaborados e socialmente apresentados como avanços de grande monta na regulação do uso da água e na democratização de 
seu aparato gestor, podem seguir reproduzindo o conteúdo das relações de poder fixadas no plano da própria localidade.

A conjuntura sociopolítica aqui analisada sugere, em termos de abordagem sociológica, que o estudo das novas instâncias de governança também requer, além da compreensão de suas dimensões institucionais (incluindo a imposição do discurso técnico das burocracias de gestão ambiental, que comumente desloca o saber tradicional para o campo da especulação, identificando-o como não-saber), também a interpretação dos modos de dominação simbólica e material construídos em conjunturas localizadas. Possivelmente o emprego de esforços desta ordem possibilitará que aspectos como os que envolvem as iniqüidades regionais no acesso à água, por exemplo, venham à tona como processos herdados e, no movimento dialético do território, eventualmente reproduzidos a partir de novas bases sociais.

\section{Referências}

ABRAM O VAY, R. O Capital Social dos Territórios: repensando o desenvolvimento rural.In: Revista de Economia Aplicada, V.4, №2, p.379-396, 2000.

ALVES, F; ASSU M PÇÃO, M .R. Reestruturação e Desregulamentação do Complexo Sucroalcooleiro: disfunções e propostas de políticas públicas. In PAULILO, Fernando;

ALVES, Francisco J. (orgs). In: Reestruturação Agroindustrial: políticas públicas e segurança alimentar regional. São Carlos: EDUFSCar, 2002, 350p. p.109-151.

BULLER, H. Regulation 2078: patterns of implementation. In: BULLER, H., WIL$\mathrm{SO}$, G.; HOLL, A. (orgs) Agri-environmental Policy in the European Union. Ashgate. England, 2000, pp.71-94.

CAM PAN HO LA, C.; SILVA, J.G. Diretrizes de Políticas Públicas para o Novo Rural Brasileiro: incorporando a noção de desenvolvimento local. In CAM PANHOLA, 
Clayton; SILVA, José G. (orgs) In: $\mathbf{O}$ Novo Rural Brasileiro: políticas públicas. Vol.4, Jaguariúna-SP: Embrapa, 2000.

CANDIDO, A. Os Parceiros do Rio Bonito: estudo sobre o caipira paulista e a transformação dos seus meios de vida. 8ạ ed. São Paulo: Duas Cidades, 1998, 284p.

CASA DA AGRICULTURA ANTÔNIO ORTIGOSSA. Convênio SAA/Prefeitura Município de Barra Bonita. Barra Bonita-SP: Escritório de Desenvolvimento Rural de Jaú, 2001, 63p.

CBH -TJ (Comitê da Bacia Hidrográfica do Tietê-Jacaré), Ata da 2a Reunião Plenária CBH-TJ, realizada no dia 27 de maio de 2004. Disponível em www.sigrh.sp.gov.br, 2004a.

CBH-TJ (Comitê da Bacia Hidrográfica do Tietê-Jacaré). Diagnóstico da Situação Atual dos Recursos Hídricos e Estabelecimento e Diretrizes Técnicas para a Elaboração do Plano da Bacia Hidrográfica do TietêJacaré. CBH-TJ/FEHIDRO. Disponível em www.sigrh.sp.gov.br, 2004b.

EURO PEAN COM MISSION, State of Application of Regulation (EEC) nr.2078/ 92: Evaluation of Agri-Environmental Programmes. DG VI Commission Working Document, VI/7655/98, Bruxelas, 1999, 96p.

FO U CAU LT, M. Microfísica do Poder. 8ªed. Rio de Janeiro: Edições Graal, 2003, 296p.

FREITAS, A.J. Direito e O utorga de U so da Água. . In SILVA, Demétrio D.; PRU SKI, Fernando F. (orgs) Recurso Hídricos e Desenvolvimento Sustentável da Agricultura. Brasília: MMA, 1997.

FU RTAD O, L.G. Pescadores do Rio Amazonas: um estudo antropológico da pesca ribeirinha numa área amazônica. Belém-PA: Museu Paraense Emílio Goeldi, 1993, 486p.

GIDDENS, A. Modernidade e Identidade. Rio de Janeiro: Jorge Zahar Editor, 2002, 233p.

GODELIER, M. Economia e Sociedade. In CARVALHO, Edgard de A. (org) Godelier - Antropologia. Coleção Grandes Cientistas Sociais. São Paulo: Ed. Ática, 1981, 208p. p.47-58. 
HABERM AS, J. Pensamiento Postmetafísico. Madrid: Taurus H umanidades, 1990, $280 p$.

LEADER EUROPEAN OBSERTATORY. Territorial competitiveness: creating a territorial development strategy in light of the LEADER experience. Dossier $n^{\circ} 6$

LEADER European Observatory, 1999, 211p.

LEFF, E. Green Production: toward an Environmental Racionality. New York-London: The Guilford Press, 1995, 168p.

LEFF, E. A Geopolítica da Biodiversidade e o Desenvolvimento Sustentável: economização do mundo, racionalidade ambiental e reapropriação social da natureza. In MARTINS, Rodrigo C.; VALENCIO, Norma F. (orgs) Uso e Gestão dos Recursos Hídricos no Brasil - Vol. 2: desafios teóricos e políticoinstitucionais. São Carlos-SP: RiMa, 2003, 293p. p.1-19.

MARSDEN, T. New Rural Territories: regulating the differentiated rural spaces. In: Journal Rural Studies. Vol. 14, nำ1, p. 107-117, 1998.

MARTINS, J.S. A Sociabilidade do Homem Simples: cotidiano e história na modernidade anômala. São Paulo: Hucitec, 2000, 212p.

MARTINS, R.C. Análise dos Impactos Sócio-Ambientais do Processo de Modernização Agrícola das Áreas de Influência dos Reservatórios de Barra Bonita e Jurumirim. Dissertação (Mestrado). Programa de Pós Graduação em Ciências Sociais - UFSCar. São Carlos, 2000, 201p.

MARTINS, R.C. A Construção Social do Valor Econômico da Água: estudo sociológico sobre agricultura, ruralidade e valoração ambiental no estado de São Paulo. Tese (Doutorado). PPG-SEA, Universidade de São Paulo, 2004a, 258p.

MARTINS, R.C. Poder e Governança nos Marcos da Regulação Ambiental em Áreas Rurais. In: Anais do XXV International Congress of the Latin American Studies Association. Las Vegas: LASA, out. 2004b, 25p.

MARTINS, R.C.; VALENCIO, N.F.L.S. Valoração dos Recursos Hídricos e Impasse Sócio-Ambiental na Agricultura Paulista: alguns desafios para a gestão de políticas públicas. In: Informações Econômicas. Instituto de Economia Agrícola, vol.33, n.10, pp. 28-40, out. 2003, 
MAZO RRA, A.P. Agri-Environmental Policy in Spain: the agenda of socio-political developments at the national end local levels. In: Journal of Rural Studies (17), p. 81-97, 2001.

PATTON, M.Q. Q ualitative Research and Evaluation Methods. 3ạed. London: Sage Publications, 2002, 179p.

PEARCE, D.; TURNER, R.K. Economics of Natural Resources and the Environment, Baltimore: The Johns Hopkins University Press, 1991.

QUEIROZ, M.I.P. Variações sobre a Técnica de Gravador no Registro da Informação Viva, São Paulo: CERU e FFLCH/U SP, 1983.

Q UEIROZ, M.I.P. Relatos O rais: do "dizível" ao "indizível". In SIMSO N, O lga de Morais von. Experimentos com Histórias de Vida (Itália-Brasil). São Paulo: Vértice, Editora Revista dos Tribunais, 1988.

RAGIN, C.C. Constructing Social Research: the unity and diversity of method. Sociology for a New Century Series, California: Pine Forge Press, 1994, 194p.

RAY, C. Territory, Structures and Interpretation - Two Cases Studies of the European Union's LEADER I Programme. In: Journal of Rural Studies, vol.14, n.1, 1998, 79-87.

RO U SSEAU, J.J. Discurso Sobre a O rigem e o Fundamento da Desigualdade entre os Homens. In: Os Pensadores, 5ạ ed. São Paulo: Nova Cultural, 1991, 320p. p.201-320.

SAHLINS, M. Cultura e Razão Prática. Rio de Janeiro: Jorge Zahar Editor, 2003, 231p.

SANTOS, B.S. A Crítica da Razão Indolente: contra o desperdício da experiência. São Paulo: Ed. Cortez, 2002, 415p.

SÃO PAULO. Relatório de situação dos recursos hídricos do estado de São Paulo. Conselho Estadual de Recursos Hídricos - CRH / Comitê Coordenador do Plano Estadual de Recursos Hídricos - CORHI. São Paulo: Poder Executivo, 2000, 128p.

SCHENEIDER, F.; VOLKERT, J. No chance for incentive-oriented environmental policies in representative democracies? A Public Choice analysis. In: Ecological Economics, n.31, p.123-138, 1999. 
SCHNEIDER, S. A Abordagem Territorial do Desenvolvimento Rural e suas Articulações Externas. In: Sociologias. Porto Alegre, n.11, p.88-125, jan/jun. 2004.

SILVA, M.A.M. Errantes do Fim do Século. São Paulo: Editora Unesp, 1999, $370 p$.

STO REY, D Issues of Integration, Participation and Empowerment in Rural Development: the case of LEADER in the Republic of Ireland. In: Journal of Rural Studies, vol. 15. n.3, p. 307-315, 1999.

TAYLOR, S.J.; BOGDAN, R. Introduction to Qualitative Research Methods. 2a ed. - New York: John W iley \& Sons, 1984, 302p.

THOMPSON, E.P. A Miséria da Teoria ou um Planetário de Erros: uma crítica ao pensamento de Althusser. Rio de Janeiro: Zahar Editores, 1981.

VEIGA, J.E. 0 Brasil Rural Precisa de uma estratégia de Desenvolvimento. Série Textos para Discussão no1. Braślia-DF: NEAD, 2001, 107p.

YLISKYLÄ-PEURALAHTI, J. Biodiversity - a new spatial challenge for Finnish agrienvironmental policies? In: Journal of Rural Studies, n.19, p.215-231, 2003.

WILSO N, G.A.; PETERSEN, J.E.; HÖLL, A. E.U. Member State Responses to AgriEnvironment Regulation 2078/92/EEC - towards a conceptual framework? In: Geoforum n.30: Pergamon, pp.185-202, 1999. 


\section{Resumo}

Temas relativos à governança de interesses sociais e de recursos ambientais fixados em territórios rurais têm recebido especial destaque na literatura sociológica recente. Envolto na temática das novas ruralidades, o debate sobre a composição de distintos interesses sociais em instâncias de gestão ambiental e gestão territorial segue demandando reflexões junto às ciências sociais. Visando contribuir com novos subsídios para tal debate, este artigo apresenta uma pesquisa socio lógica sobre conflitos territoriais e político-institucionais na gestão das instâncias regionais de política de águas no estado de São Paulo (Brasil). Através de um estudo de caso, realizado com recursos de técnicas qualitativas de pesquisa social, o trabalho discute como distintos interesses agrícolas se relacionam com instrumentos modernos de regulação pública ambiental - notadamente os Comitês de Bacias Hidrográficas. A hipótese geral do estudo é a de que a democracia formal representada por estas instâncias locais de regulação pública ambiental não resiste aos fundamentos das estruturas locais de dominação política e econômica.

Palavras-chave: ruralidade, sociedade e recursos hídricos, representações sociais, poder local. 


\section{Social representations, institutions, and conflicts in water management in rural territories}

\section{Rodrigo Constante Martins}

Issues related to the governance of social interests and environmental resources established in rural territories have been highlighted in recent sociological literature. Surrounded by the issues of new ruralities, the debate about the makeup of distinct social interests within environmental management and territorial management bodies keeps demanding reflection from social sciences. In order to contribute new subsidies to such debate, this article presents a new sociological research about the territorial and political-institutional conflicts in the management of regional bodies for water policy in the state of São Paulo (Brazil). Through a case study made with qualitative techniques for social research, the work discusses how distinct agricultural interests relate to modern tools for environmental pubic regulation notably the Basin Committees. The study's general hypothesis is that formal democracy represented by those environmental public regulation bodies cannot stand the fundaments of local structures of political and economic domination

Key words: rurality; society and water resources; social representations; local power 